\title{
O FANTÁSTICO, A ALEGORIA E A OBRA DE JOSÉ SARAMAGO
}

Odil José de OLIVEIRA FILHO*

RESUMO: Contrapondo o duplo sentido da alegoria à constituição formalmente provocadora do fantástico, hesitante entre o sentido e o não-sentido, o artigo busca acompanhar alguns traços da tensão entre a alegoria e o fantástico na obra do escritor português José Saramago.

PALAVRAS-CHAVE: Fantástico; Alegoria; José Saramago; Romance.

\section{O “âmago” do fantástico}

$\mathrm{Na}$ interpretação, hoje já clássica, de Tzvetan Todorov (1975), o elemento distintivo dos textos literários do gênero fantástico estaria na "hesitação", experimentada, em primeiro lugar, pelo personagem envolvido no relato, indeciso em considerar as situações que enfrenta como simples ilusão dos sentidos ou como manifestação inexplicável de fatos cujas leis lhes são desconhecidas e estranhas. Tomando-a como traço característico do fantástico, Todorov serve-se da idéia da hesitação para distingui-lo dos outros gêneros correlatos, como o maravilhoso e o estranho, nos quais a incerteza seria rompida, seja pela assunção declarada dos aspectos alucinatórios (o estranho) ou pela entrada num universo francamente sobrenatural (o maravilhoso).

Inscrito, assim, na vivência psicológica do personagem, o efeito da incerteza do fantástico visaria, afinal, a jogar com o leitor, procurando discursivamente colocá-lo na mesma posição hesitante entre o mundo conhecido, regido pelas leis naturais, e o desconhecido, tomado pelas esferas do sobrenatural. Para Todorov, a hesitação estaria prevista no texto para atingir o leitor, cabendo, portanto, a este a tarefa final de manter ou não a incerteza peculiar ao gênero, na atividade interpretativa que vier a proceder. Diz:

Quando o leitor sai do mundo dos personagens e volta à sua prática própria (a de um leitor), um novo perigo ameaça o

\footnotetext{
* Doutor em Letras pela Universidade de São Paulo (USP) e Professor de Literatura Portuguesa dos Cursos de Graduação e Pós-Graduação em Letras da Faculdade de Ciências e Letras da Universidade Estadual Paulista “Júlio de Mesquita Filho", UNESP/Campus de Assis-SP.
} 
fantástico. Perigo que se situa ao nível da interpretação do texto. (TODOROV: 1975, p.37)

Dessa forma, o fantástico implicaria não só a ocorrência de um acontecimento estranho, que provocaria um efeito de hesitação no personagem e no leitor, mas também uma certa maneira de ler, que, para Todorov, não poderia ser nem uma leitura "poética" - já que a poesia instaura uma dimensão outra da palavra e o fantástico implica necessariamente a ficção - , nem uma leitura "alegórica" (TODOROV: 1975, p.38).

Ora, o "perigo" representado pela interpretação alegórica de um texto fantástico estaria, para Todorov, na possibilidade de desvanecimento da hesitação própria do gênero, uma vez que pressuporia a consideração de um "alhures", fora do próprio texto, afastando o leitor do efeito de estranhamento previsto na esfera da produção artística.

Tal posição implica, de alguma forma, um encaramento mais ou menos desconfiado da alegoria, muito próximo, aliás, do pensamento romântico sobre a arte e que pode ser notado em outro livro de Todorov, Teorias do símbolo (de 1977). Como se sabe (e diz o próprio autor), tal estudo é organizado em função de acompanhar as teorias construídas sobre o símbolo, com interesse central no período de uma crise da concepção clássica, ocorrida em fins do século XVIII, e o surgimento de uma nova concepção, a romântica, que, no ver de Todorov, seria "triunfante até hoje" (TODOROV: 1996, p.10). Ali, sintetizando o pensamento dos principais mentores do Romantismo alemão, Todorov procura apontar as sobrevivências desse pensamento na Modernidade, principalmente aquelas relacionadas com as idéias dos românticos sobre a intransitividade e a autonomia da arte em relação à realidade, com o intuito, como diz Novalis, de combater a tirania do princípio de imitação.

Filiando-se declaradamente a essa tradição, não é estranho, pois, que Todorov veja na figura da alegoria uma ameaça ao fantástico ou, mais especificamente, na interpretação alegórica, a destruição da ambigüidade artística constitutiva do texto - de todo texto, principalmente do texto fantástico.

É preciso ressaltar, no entanto, que Todorov não deixa de relacionar o pensamento artístico dos primeiros intelectuais burgueses ao clima de otimismo e euforia que os dominava àquela altura quanto às possibilidades da "literatura futura", que, segundo almejavam, abandonaria os valores absolutos e hierárquicos da imitação, para instaurar a autonomia das palavras, numa junção verdadeiramente republicana 
entre o poético e o político. Cita, nesse sentido, um trecho dos fragmentos de Novalis que vale a pena transcrever:

Como será belo quando se ler somente belas composições, obras de arte literária. Todos os outros livros são apenas meio esquecidos assim que deixam de ser úteis, o que os livros não continuam a ser por muito tempo. (Apud TODOROV: 1996, p.225)

Pode-se notar, no trecho, a indisfarçada oposição de Novalis entre obra de arte e utilidade, que, no fundo, parece remeter à célebre oposição veiculada pelos românticos entre símbolo e alegoria, e que, durando pelos tempos afora, criou uma espécie de preconceito crítico contra a alegoria, encarada como responsável pela caducidade dos textos que nela se sustentam, enquanto os simbólicos ou metafóricos atingiram a perenidade artística pela sua autonomia em relação ao tempo que os viu nascer.

Voltando à teorização todoroviana sobre o fantástico, é verdade que ela não opõe o texto fantástico ao alegórico - que encontra seu campo de ação, em sua teoria, na esfera do maravilhoso utilizado como recurso pelas intenções moralizantes da fábula. No entanto, a oposição que institui entre o gênero e a leitura alegórica acaba por ressoar como se houvesse, de fato, uma contradição inconciliável entre fantástico e alegoria - o que poderia levar à idéia de que esses modos de compor seriam, por natureza, excludentes.

Centrado numa posição imanentista, pós-romântica, Todorov não se preocupa em cogitar se, na esfera da produção, poderia haver uma "intenção alegórica", um projeto de representação do mundo, problematizado formal e esteticamente por meio de um texto que assume a hesitação fantástica como fulcro de sua composição artística.

\section{O temor do não-sentido}

É justamente essa visão problematizadora do mundo pelo Romantismo que pode ser encontrada na obra de Michael Löwy e Robert Sayre, Romantismo e Política (1993). Apontam os autores, dentro do movimento, a ocorrência (na esteira de Lukács) de tendências anti-capitalistas, no início do século XIX, representadas por obras “deliberadamente não-realistas, fantásticas", dominadas por uma espécie de "irrealismo crítico", como forma de contestação ao prosaísmo burguês (1993, p.15). Para os autores, o sentimento que anima os escritores dessas tendências é o da nostalgia (Novalis e E.T.A.Hoffmann são citados como exemplos), em que "a alma, sede do humano, vive 
aqui e agora longe do seu verdadeiro lar ou de sua verdadeira pátria (Heimat) e de que o isolamento tornou-se a experiência fundamental" (1993, p.22).

No mesmo sentido, num nível mais antropológico do que político, Roger Caillois também faz coincidir o surgimento da literatura fantástica européia com a ascensão do Romantismo, como reação - própria de todo fantástico - insubmissa ante concepções racionalistas dos fenômenos, eclodindo, pois, em fins do século XVIII, como compensação de um excesso de racionalismo e contestação "à imagem de um mundo sem milagre, submetido a uma causalidade rigorosa" (CAILLOIS: 1966, p.14).

Mais recentemente, Irlemar Chiampi, ao aproximar as formas do romance hispano-americano à tradição do fantástico ocidental, procede justamente a uma reavaliação da teoria de Todorov, retomando idéias que se afinam em certos pontos com as de Caillois e mesmo de Löwy e Sayre. Para Chiampi, a hesitação, a inquietação provocada no leitor pelo texto fantástico representa, na verdade, o "temor do nãosentido: o leitor representado é a figuração da perplexidade diante de uma significação ausente" (CHIAMPI: 1980, p.55). E mais à frente:

[...] o medo (elemento emotivo) do não-sentido (elemento intelectivo) só pode ser uma provação para o leitor, desde que seja motivado pelo seu próprio desejo de preservar a norma de seus quadros sócio-cognitivos. Por isso o sentimento de Umheilich (estranheza inquietante) [...] aplica-se com justeza ao efeito de fantasticidade. O leitor teme o 'não-familiar'; o novo, enquanto signo da outridade que ameaça a sua ordem de valores estabelecidos. (1980, p.68)

Assim, no contexto da ficção hispano-americana, Chiampi entende que o realismo maravilhoso estaria a propor um reconhecimento inquietante do mundo, "trazendo de volta o Heimlich, o familiar coletivo (mitologia, magia, tradições populares), oculto e dissimulado pela repressão da racionalidade" (1980, p.69).

Analisado por um prisma mais sociológico, pode-se entender, afinal, que a hesitação estrutural do fantástico é, de algum modo, índice de sua problematização do mundo e manifestação formal de uma atitude insubmissa aos sentidos dominantes, instituindo pela contradição, por uma postura de irrealismo crítico, a sua dimensão ideológica (ou contra-ideológica) - e, portanto, alegórica.

\section{Alegoria e melancolia}


Do ponto de vista estético, não há como não considerar a alegoria como uma séria ameaça à compleição artística de uma obra. Dominando a intenção alegórica, a forma liqüefaz-se em pura transparência, o conteúdo sobreleva-se, imiscível, e, com o tempo, evaporada a forma, petrifica-se num impuro não-sentido. No entanto, no melhor dos casos, ou seja, quando não milita disfarçadamente em favor de uma causa ideológica, a alegoria tem servido como recurso extremo de manifestação expressiva, principalmente no interior de um mundo visto ou vivido como agônico, desesperançado e sem futuro, e que, por isso, sente o tempo presente como perda irremediável.

Nesses contextos problemáticos para a vida da cultura e, portanto, para a manifestação das expressões artísticas, o recurso à alegoria responderia a uma necessidade urgente de tentativa de apreensão da realidade contemporânea ao artista, o que geralmente ocorre em momentos históricos repressivos ou sentidos como decadentes e transitórios.

Talvez por isso, pela observação desses aspectos, é que o estudo de Walter Benjamin sobre o drama barroco alemão seja fundamental para quaisquer considerações sobre a alegoria. E isso porque o seu desvelamento da atitude espiritual do alegorista barroco como uma postura profundamente melancólica, acediosa, pode, na verdade, ser aplicada a todo aquele que, pressionado pelos problemas do presente, entrega-se à tarefa, quase sempre inútil e ilusória, de apreendê-los e fixá-los por meio de imagens que possam causar estupefação e que, por isso mesmo, envelhecem. Dessa forma, para resistir a essa sua tendência à auto-absorção, é que a alegoria precisaria desenvolver-se de formas sempre novas e surpreendentes - em contraste radical com o "símbolo", que, como perceberam os mitologistas românticos, permanece tenazmente igual a si mesmo.

Diz Benjamin:

Se o objeto se torna alegórico sob o olhar da melancolia, ela o priva de sua vida, a coisa jaz como se estivesse morta, mas segura por toda a eternidade, entregue ao alegorista, exposta a seu bel-prazer. Vale dizer, o objeto é incapaz, a partir desse momento, de ter uma significação, de irradiar um sentido; ele só dispõe de uma significação, a que lhe é atribuída pelo alegorista. (BENJAMIN: 1984, p.205-6)

Ora, no interesse das idéias desenvolvidas neste estudo, não parece despropositado apontar uma forte semelhança nas atitudes do escritor alegórico e do fantástico diante do mundo a representar, já que ambos parecem imbuídos de um projeto 
de problematização dos sentidos reinantes num contexto de significações flutuantes e indecisas, percebidas como danosas e insuficientes. Porém, o que mais parece irmanálos é uma espécie de temor de cair no "não-sentido" na tentativa de contrapor-se ao senso comum; seja, no caso do primeiro, para converter a significação na chave de um saber oculto, num emblema; seja, no caso do segundo, para introduzir a visão de um mundo dominado pela hesitação e pela ambigüidade intranqüilizadora.

\section{Um escritor entre o alegórico e o fantástico: José Saramago}

Um outro ponto a aproximar o alegórico e o fantástico está na constatação mais ou menos evidente de que o primeiro invariavelmente serve-se de vários elementos do segundo para constituir-se como tal e que (como vimos anteriormente) o que este último busca, ao fim, é assumir a ressonância significativa histórica que o outro ambiciona atingir mais urgentemente.

Ainda que, de fato, todo texto artístico possa ser visto como estruturado em função dessa tensão fundamental entre o alegórico e o fantástico, os termos que aqui estão sendo considerados visam ao reconhecimento de ambos como gêneros específicos do discurso literário, sobretudo o último, que já compõe, hoje, um domínio particular na tradição literária.

Por isso, em função dos interesses desta discussão de raiz genológica, tomar-seá, daqui em diante, como base da reflexão, a obra de um escritor contemporâneo em que a tensão entre alegoria e fantástico parece atravessar toda a já significativa produção concebida até agora. Trata-se do escritor português José Saramago, que, além de vir escrevendo livros com significativas repercussões entre o público atual, apresenta textos em que as tendências fantásticas e alegóricas estão postuladas, ora de forma equilibrada, ora de forma desequilibrada, gerando, num caso, parece o melhor de sua lavra e, no outro, o menos significativo do que tem produzido.

Com efeito, sem querer forçar a hipótese interpretativa aqui utilizada, não parece exagero afirmar-se que a tensão entre as tendências alegóricas e fantásticas tem sido o desafio que Saramago vem enfrentando desde o início de sua trajetória artística. Formado no interior da ambiência cultural do Neo-Realismo, em que a necessidade de resistência à opressão fascista obrigava o artista quase que inevitavelmente a posicionarse ante o presente e, portanto, a assumir a arma alegórica da denúncia urgente da situação, mas, ao mesmo tempo, dominado interiormente por um certo gosto pelo 
nonsense e pelo inusitado (certo fundo "barroquista", que muitos apontam em sua obra), pode-se perceber uma espécie de embate dessas duas tendências em seu chamado "período formativo".

Considerando o elenco dos livros desse período, pode-se notar isso mais claramente. Dessa forma, após a estréia, em 1947, com um obra de juventude, de inevitáveis influências do Realismo-Naturalismo e, porventura, de Eça de Queirós, os textos de Saramago parecem realmente oscilar entre um projeto de apreender e representar alegoricamente o mundo e o desejo de extravasar a criatividade escritural que anima a sua vocação estética. Tal fato pode ser observado já nos seus livros de crônicas, Deste mundo e do outro (1971) e A bagagem do viajante (1973), que buscam interpenetrar a "vida ao rés-do-chão" (CANDIDO: 1982) própria do gênero cronístico, ao "outro mundo", o da imaginação, do fantástico, da ficção - e daí, para ficar nos exemplos mais evidentes, textos como A aparição, Os olhos de pedra e Alice e as maravilhas, de Deste mundo e do outro, e Moby Dick em Lisboa e O lagarto, de A bagagem do viajante.

No mesmo sentido, podem ser vistos os contos do livro Objecto Quase (1978). São seis contos em que fantástico e alegoria convivem: ora harmoniosamente, como em Desforra e Cadeira; ora propendendo, mais ou menos francamente, para o alegórico, como em Embargo, Refluxo, Coisas e Centauro.

Os casos mais decisivos, no entanto, para o que aqui interessa, são os desse estranho livro que é $O$ ano de 1993 e do romance Manual de pintura e caligrafia (ambos de 1976). O primeiro tem causado alguma dor de cabeça aos leitores críticos de Saramago, que o tem tentado enquadrar genologicamente numa espécie de solução híbrida entre a prosa e a poesia, como um poema narrativo ou como uma narrativa poética. De certa maneira, O ano de 1993 vem a cumprir curiosamente um desígnio de Novalis, quando projetava os modos de ser de uma "Literatura futura"- como se viu anteriormente -, e cujo fragmento Todorov transcreve em seu Teorias do símbolo:

Narrativas desconexas, incoerentes, todavia com associações, tal como os sonhos. Poemas perfeitamente harmoniosos e belos em suas palavras perfeitas, mas também sem coerência, nem sentido algum, com no máximo duas ou três estrofes inteligíveis - que devem ser puros fragmentos das coisas mais diversas. A poesia, a genuína, pode quando muito ter grosso modo um sentido alegórico, como a música etc., um efeito indireto. (Apud TODOROV: 1996, p.225-6) 
Não há como não reconhecer na antevisão de Novalis aquilo que viria a tornar-se o cerne do Surrealismo, tendência em que justamente $O$ ano de 1993 tem sido enquadrado (V. MARTINHO: 1999,p.21-33) e cuja aproximação deveria responder à tentativa de Saramago de conciliar a necessidade da denúncia social aos traços peculiares de seu estilo artístico.

Tal questão é, aliás, o elemento fundamental de Manual de pintura e caligrafia, consubstanciada nas reflexões autobiográficas do pintor em crise criativa a respeito da natureza e das funções da Arte. Em seu drama, dividido entre o seu trabalho como pintor figurativo e as solicitações interiores para dar vazão a uma expressão mais verdadeira da sua visão artística do mundo (ao que tudo indica, de raiz surrealista), encena-se também a luta de Saramago para encontrar a saída, a síntese procurada para a estruturação de sua própria obra. Veja-se, nesse sentido, uma das reflexões de H. a respeito das relações entre a expressão artística e o sonho:

Devo dizer, porém, para que alguma claridade fique, que as últimas páginas foram escritas estando eu muito e bem acordado, que o que nelas de sonho se descreve não é um sonho só nem uma só noite, mas pedaços soltos de sonhos repetidos, alguns invariavelmente repetidos, e para o efeito e a conveniência de agora organizados numa incoerência coerente. Sei de pintura o bastante, e agora o suficiente de caligrafia, para perceber e tentar praticar que poucas coisas exigem tanta organização como a expressão da incoerência. Falo da expressão, não do simples manifestar-se. (SARAMAGO: 1976, p.226)

No entanto, a trajetória do narrador-personagem, da crise expressiva à autorevelação artística, sustentar-se-á, em grande parte, no papel cumprido por M., a mulher que virá para desvendar-lhe o amor e o mundo - o que revestiria a personagem de um claro matiz alegórico, já que, como diz Horácio Costa, “ao induzir H. à História[...] M. adquiriria um cariz antes alegórico que romanesco", denunciando "uma dificuldade do autor no seu primeiro romance 'adulto' para construir um enredo tão completo, em termos da economia do relato, como os urdirá na sua obra romanesca mais recente" (COSTA: 1997, p.315-7).

De fato, tendo-se em conta os romances escritos por Saramago durante a década de 80, que compõe a fase mais conhecida e reconhecida do Autor, pode-se perceber ter sua escritura encaminhado-se para solucionar os dois impulsos básicos que, no interior dela, vinham se contraditando. Assim, sabendo-se que tal fase de sua produção 
romanesca é dominada por um trabalho de aproximação entre a ficção e a História, pode-se entender que essa junção acabou por canalizar, para um mesmo curso expressivo, as tendências fantásticas que atraíam o Autor e suas preocupações com a representação do mundo.

Inaugurada com o romance Levantado do chão (1980), essa etapa apresenta momentos luminosos de síntese equilibrada entre o fantástico e a alegoria, em que o compósito formado entre esses dois vetores fundem-se indissoluvelmente, como são os casos de Memorial do convento (1982) e de O ano da morte de Ricardo Reis (1984). Dessa época é também, no entanto, o romance A Jangada de Pedra (1986), em que a urgência da discussão sobre a entrada de Portugal no Mercado Comum Europeu faz com que Saramago valha-se claramente das armas combativas da alegoria para posicionar-se ante a situação. No mesmo aspecto e encerrando essa fase de sua produção, aparece, em 1991, o romance O evangelho segundo Jesus Cristo, em que Saramago lança mão de uma verdadeira "alegoria dos teólogos" ( V.HANSEN:1986) para engendrar uma alegoria de cunho interpretativo das escrituras sagradas do Cristianismo.

A partir daí, abandonando o projeto de provocação à visão histórica oficial, Saramago volta-se para encarar a realidade contemporânea, dando início a uma seqüência de textos de caráter dominantemente alegórico, inaugurada com o hoje célebre (já que transformado em filme famoso) Ensaio sobre a cegueira ( 1995) e continuado por textos como O conto da ilha desconhecida (1998), A caverna (2000), Ensaio sobre a lucidez (2004) e As intermitências da morte (2005). Trata-se do período em que sua obra conhece um alcance verdadeiramente internacional (confirmado e corroborado, em 1998, pela atribuição do Prêmio Novel de Literatura), o que possivelmente tenha levado o escritor a empreender uma espécie de balanço de sua trajetória, por meio das notações diarísticas dos Cadernos de Lanzarote (1994 a 1998) e de As pequenas memórias (2006).

Não se podendo ainda avaliar adequadamente as conseqüências causadas pela dominância alegórica nessas obras para a sua sobrevivência futura, o mais provável, porém, é que outras duas obras, ainda não mencionadas aqui, possam consegui-lo, justamente por atingirem aquele equilíbrio entre a alegoria e o fantástico de que se vem tratando: são elas os romances Todos os nome (1997) e O homem duplicado (2002). Mesmo que tal tipo de especulação possa soar como despropositada, há razões para 
acreditar que possa vir a concretizar-se, pelo menos nas cogitações de um leitor futuro que vier a tomar o conjunto todo da obra de Saramago. E isto porque as duas obras referidas compõem uma tendência no interior da produção saramaguiana, que pode ser percebida mais explicitamente no tratamento que dão a um mesmo tema: o da solidão. Nesse âmbito, Todos os nomes e $\mathrm{O}$ homem duplicado perfilam-se a outros textos anteriores, a saber, História do cerco de Lisboa, O ano da morte de Ricardo Reis e Manual de pintura e caligrafia, estruturando um conjunto de romances em que a figura de um "herói problemático" confronta-se com um mundo a que não se sente mais integrado.

Centrado, pois, nessa tópica fundamental da forma romanesca, esses textos fogem um pouco ao pendor dominante, ainda de raiz neo-realista, de Saramago para a construção de seus "personagens-grupo", nos quais, talvez justamente por isso, a propensão alegórica, à abstração, mesmo a certo esquematismo - no pior dos casos -, pode ser percebida.

O curioso é que, tomando-se apenas o subconjunto composto por esses romances, pode-se notar o mesmo amadurecimento da escritura saramaguiana que tem sido costumeiramente apontado para o conjunto da obra, visto que é formado por textos do período formativo, da fase histórica e da etapa mais recente de sua produção artística. No entanto, se no conjunto dominante(que tem conhecido muito maior repercussão entre o público e mesmo entre a critica contemporânea) as relações de congruência estabelecem-se pela reiteração de um mesmo projeto estético de base radicalmente humanista, no subgrupo indicado, o exame da condição humana parte do desajustamento do herói, isolado e tomado por uma crise melancólica que o move a empreendimentos inconseqüentes, irracionais, fantásticos e, em alguns casos, sem possibilidade de redenção.

Nesses últimos casos é que podem ser enquadrados Todos os nomes e, principalmente, O homem duplicado, no qual, aliás, logo no início do texto, explicitamse as suas ligações com as obras anteriores. Diz o narrador-autor sobre a tipologia psicológica desse seu personagem de estranho nome, chamado Tertuliano Máximo Afonso, que vai viver a alucinada aventura de descobrir, e a todo custo tentar encontrar, um homem que é o seu duplo:

O que por aí mais se vê, a ponto de já não causar surpresa, é pessoas a sofrerem com paciência o miudinho escrutínio da solidão, como foram no passado recente exemplos públicos, 
ainda que não especialmente notórios, e até, em dois casos, de afortunado desenlace, aquele pintor de retratos de quem nunca chegamos a conhecer mais que a inicial do nome, aquele médico de clínica geral que voltou do exílio para morrer nos braços da pátria amada, aquele revisor de imprensa que expulsou uma verdade para plantar no seu lugar uma mentira, aquele funcionário subalterno do registro civil que fazia desaparecer certidões de óbito, todos eles, por casualidade ou coincidência, formando parte do sexo masculino, mas nenhum que tivesse a desgraça de chamar-se Tertuliano, e isso terá decerto representado para eles uma impagável vantagem no que toca às relações com o próximo. (SARAMAGO: 2002,p.10)

As remetências às obras, além de jogarem com as questões da autoria, inserem algumas nuances importantes para o que aqui interessa fazer notar. Assim, sabendo-se que o "pintor de retratos" é o personagem H. do Manual de pintura e caligrafia, o "médico de clínica geral que voltou do exílio" é o Ricardo Reis de $O$ ano da morte de Ricardo Reis, o "revisor" é o Raimundo Silva da História do cerco de Lisboa e, finalmente, que o "funcionário subalterno do registro civil" é o Senhor José de Todos os nomes, constata-se que o próprio Autor (suposto, no caso) burilou-lhes trajetórias distintas, visto que dois dos casos são culminados por um "afortunado desenlace". Já se ressaltou acima como isso se dá no Manual, onde a motivação encontrada no amor por uma mulher redime o pintor $\mathrm{H}$. de sua crise melancólica e de seu cultivar do "miudinho escrutínio da solidão" - o que também sucede ao revisor Raimundo Silva e seu amor por Sara, em História do cerco de Lisboa, ainda que, no último texto, a redenção amorosa não assuma o acentuado peso alegórico que recebera no primeiro.

Restam-nos os casos do Senhor José e de Ricardo Reis, excluídos, pelo próprio Autor, da possibilidade de concluírem suas histórias por um "afortunado desenlace". Quanto ao primeiro, já velho, talvez, de fato, não lhe caísse bem um final feliz romântico, apesar de sua procura obsessiva e apaixonada pela identidade da mulher desconhecida. Em todo o caso, é essa sua desesperada busca para superar os limites entre a vida e a morte que dá grandiosidade à sua utopia e à sua solidária solidão. Como percebe Adriano Schwartz, ele também, como a maioria dos protagonistas de Saramago, cumpre um "trajeto rumo à positividade", do qual estaria excluído apenas Ricardo Reis (SCHWARTZ: 2004, p.164-5).

Quanto a este último, diz Schwartz que é o único que recebe, por parte do narrador saramaguiano, um tratamento de irônico desdém: "O narrador não gosta muito dele e não faz grande esforço para esconder isso" (2004,p.43). Tal notação também 
poderia ser aplicada ao caso do relacionamento entre o narrador e o personagem Tertuliano Máximo Afonso de $O$ homem duplicado.

Ora, nos termos aqui discutidos, pode-se entender que as narrativas protagonizadas tanto por Reis, quanto por Tertuliano e mesmo pelo Senhor José, resistindo à "positividade", estão, em verdade, superando e equilibrando o pendor alegórico básico da escritura de Saramago, atingindo, assim, um tom de inquietude e negatividade - como vê Schwartz - próprio do romance da Modernidade. Resta apenas acrescentar que isso é conseguido em função, enfim, de uma liberação do elemento fantástico da tutela alegórica, o que, ainda que impeça o leitor de compartilhar os eflúvios reconfortadores e esperançosos de um "afortunado desenlace", pode proporcionar-1he, por outro lado, o "reconhecimento inquietante" de uma vida, que, no final das contas, é alegoricamente (mesmo que melancolicamente ) também a sua.

\section{Referências Bibliográficas:}

BENJAMIN, Walter. Origem do drama barroco alemão. Trad. Sergio Paulo Rouanet. São Paulo: Brasiliense, 1984.

CAILLOIS, Roger. De la féerie à la science-fiction. In: Anthologie du

fantastique. Paris: Gallimard, 1966. p.7-24.

CANDIDO, Antonio. A vida ao rés-do-chão. In: ANDRADE, Carlos Drummond de et al. Para gostar de ler. São Paulo: Ática, 1982. p. 5-13.

CHIAMPI, Irlemar. O realismo maravilhoso: Forma e ideologia no romance hispano-americano. São Paulo: Perspectiva, 1980.

COSTA, Horácio. José Saramago - O período formativo. Lisboa: Caminho, 1997.

HANSEN, João Adolfo. Alegoria: Construção e interpretação da metáfora. São Paulo: Atual, 1986.

LÖWY, Michael e SAYRE, Robert. Romantismo e política. Trad. Eloísa de Araújo Oliveira. Rio de Janeiro: Paz e Terra, 1993.

MARTINHO, Fernando J.B. Para um enquadramento periodológico da poesia de José Saramago. In: COLÓQUIO/LETRAS n $\mathbf{n}^{\mathbf{1 5 1}}$ 152, janeiro-junho, 1999, p.21-33.

SARAMAGO, José. Manual de pintura e caligrafia: Ensaio de romance. Lisboa: Moraes Editores, 1976.

. O homem duplicado. São Paulo: Companhia das Letras, 2002.

SCHWARTZ, Adriano. O abismo invertido: Pessoa, Borges e a inquietude do romance em $O$ ano da morte de Ricardo Reis. São Paulo: Globo, 2004.

TODOROV, Tzvetan. Introdução à literatura fantástica. Trad. Maria Clara Correa Castello. São Paulo: Perspectiva, 1975.

. Teorias do símbolo. Trad. Enid Abreu Dobránszky. Campinas: Papirus, 1996. 